\title{
The economic impact of educational training assessed by the Handling Questionnaire with three inhalation devices in asthma and Chronic Obstructive Pulmonary Disease patients
}

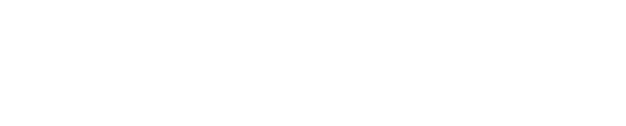

Roberto W Dal Negro' Massimiliano Povero ${ }^{2}$

'National Centre for Respiratory Phamacoeconomics and Pharmacoepidemiology - CESFAR, Verona, ${ }^{2}$ AdRes Health Economics and Outcome Research, Torino, Italy
Correspondence: Massimiliano Povero AdRes Health Economics and Outcome Research, Via Vittorio Alfieri, I7, 10123 Torino, Italy

Tel +39 0117651239

Email m.povero@adreshe.com
Background: The usability of inhalation devices depends on several factors, eg, the drug to inhale, device handling, and patients' training. Usability is then presumed to have economic consequences.

Aim: To assess and compare the cost of patients' training for proper usability of Breezhaler and Genuair (both dry powder inhalers) and Respimat (a soft mist inhaler) in asthma and chronic obstructive pulmonary disease (COPD) outpatients.

Methods: The acceptance and handling of the three devices were investigated by means of the Handling Questionnaire. The time spent in specific training for ensuring a proper actuation and the corresponding costs were also calculated. Linear and logistic regressions were used in order to investigate the factors influencing proper handling of the devices. A significance level of $P<0.05$ was accepted.

Results: According to both the patients' and the nurse's judgments, Genuair and Respimat were perceived as the easiest devices to use, while Breezhaler required the highest number of attempts for achieving the first proper actuation ( $2.6 \mathrm{vs} 1.6 ; P<0.0001)$. The total training cost per patient (including the nurse's time for demonstration and that for attending the patients' maneuvers) was $€ 1.38 \pm € 1.21$. Breezhaler was found to be the most expensive as the cost per patient was $€ 2.35 \pm € 1.26$, which was three to four times higher than that of Genuair and Respimat (both devices involved a cost of $<€ 1$ per patient, with negligible differences between each other). Asthma and COPD patients showed a similar trend, with better outcomes reported for asthma patients probably due to lower age.

Conclusion: Substantial differences were found to exist in patients' acceptability and handling of the three devices. The economic impact of specific training was also different and strictly related to the comprehension of the procedure for actuation of each device. Respimat as a soft mist inhaler and Genuair as an metered-dose inhaler proved to be the most convenient in economic terms also.

Keywords: device usability, patient preference, economic impact of training, Handling Questionnaire, Breezhaler, Genuair, Respimat, bronchial asthma, COPD

\section{Introduction}

Patients' acceptability of inhalation devices still remains a crucial point to investigate because its role in affecting the effectiveness of respiratory therapy and of related outcomes is high, indeed, and ever increasing. ${ }^{1-4}$

Acceptability and preference of different devices has been extensively investigated for many years and several critical aspects have been focused upon, ${ }^{1-5}$ particularly when investigated by means of validated instruments. ${ }^{6-8}$ 
The economic impact and sustainability of nursing activities and training aimed to ensure a proper use of devices has never been investigated in subjects with persistent airway obstruction, and the corresponding cost has never been compared among different devices, to our knowledge.

A recent study carried out in asthma and chronic obstructive pulmonary disease (COPD) patients compared the extent of training required for explaining and showing the correct inhalation procedures of three different devices before achieving their first proper actuation, and results proved dramatically different in terms of time of specific training required. ${ }^{5}$

The aim of the present study was to calculate and compare the economic impact of specific training aimed at allowing the first proper use of two dry powder inhalers (DPIs) and one soft mist inhaler (SMI) in obstructive outpatients, ie, all patients with obstructive airway disease (candidated for DPI utilization, potentially).

\section{Methods}

The study was approved by CEMS-Centro Medico Specialistico, Verona (Italy) and all patients gave their written informed consent to the study. Breezhaler (B) and Genuair (G) as DPIs and Respimat (R) as an SMI were previously investigated ${ }^{5}$ in order to assess their acceptability and check the patients' most critical steps in their usability, by means of the Handling Questionnaire, which is an investigational tool covering several domains of patients' requirements. ${ }^{6}$

First, the functioning of each device was shown to each patient in a random order by an expert nurse institutionally and specifically involved in respiratory educational programs.

In the second phase of the study (ie, after giving careful instructions of functioning of each device), patients were required to prepare each actuation by themselves, while the nurse was monitoring the patients' procedure of use. The nurse also noted their critical steps, counted the number of attempts needed for actuating the device effectively, and measured the time (in seconds) spent. Then, the subjects were requested to report and specify the reasons for choosing it, once their preference, once they experienced the device directly. Moreover, at the end of the study, the nurse added her own comments to the patients' ones, in order to compare the two points of view for each device.

As the three devices to compare were different in terms of the number of maneuvers required for their actuation, they were presumed to be different also in terms of patients' comprehension. Consequently, the time spent by the nurse in explaining and demonstrating the proper functioning of each device was measured (in seconds) together with the corresponding time required by the patients for practicing each device properly and effectively. After the third attempt, the duration of nurse instruction was not further timed because all further attempts were presumed to be of the same duration as the third attempt.

Devices were then investigated and compared in terms of cost involved in their educational training, such as the cost corresponding to the time spent by the expert nurse for explaining and demonstrating exhaustively how to use each device properly. The nurse's cost per minute was calculated stemming from the mean annual salary of a professional hospital nurse ${ }^{9}$ divided by 1,512 hours per year (eg, 36 hours/week for 42 working weeks/year); the cost was then adjusted to 2014 value by using figures from the Italian consumer price index. ${ }^{10}$

Differences among devices were assessed by using appropriate statistical tests such as the Welch test for normally distributed variables, the Wilcoxon test for not normally distributed variables, $\chi^{2}$ test, and the analysis of variance test. All data were expressed as mean \pm standard deviation or as absolute numbers and percentage, as appropriate. A $P$-value $<0.05$ was considered significant for all statistical tests. All analyses were performed using computer software R 3.1.2 (R Core Team R, Vienna, Austria). ${ }^{11}$

Finally, a subgroup analysis was also carried out according to patients' original disease (ie, bronchial asthma or COPD), in order to investigate whether their original respiratory condition might be associated with a different understanding of procedures and a different training-induced economic impact.

\section{Results}

The number of maneuvers required for actuating each device and the characteristics of 333 consecutive outpatients investigated are reported in Table 1, together with the mean duration of the nurse's training sessions and the corresponding time spent for patients' operational attempts.

Device B proved the most difficult to use when in the patients' hands. Device B required the highest number of attempts before achieving the first proper actuation (2.6 vs 1.6 vs both devices $\mathrm{G}$ and $\mathrm{R}, P<0.0001)$ and had the lowest success rate after the first training session (20\% vs 56\% with G and 62\% with R) (Table 1).

When only patients who failed the first attempt were considered, device $\mathrm{G}$ required less attempts than the other two (2.4 vs 2.7 for R, $P<0.05$, and 3.0 for $\mathrm{B}, P<0.0001$ ).

Total time spent in learning how to use the device properly was found to be the highest with device $\mathrm{B}(P<0.0001)$, because both the nurse's explanation time and the time required by the patients for preparing the inhalation properly were the longest. In particular, total time required for a proper 
Table I Characteristics of devices tested and differences in usability

\begin{tabular}{|c|c|c|c|}
\hline & B & G & $\mathbf{R}$ \\
\hline \multicolumn{4}{|l|}{ Device characteristics } \\
\hline Maneuvers $(\mathrm{n})^{*}$ & 7 & 3 & 4 \\
\hline \multicolumn{4}{|l|}{$\begin{array}{l}\text { Duration of nurse instruction } \\
\text { (seconds) }\end{array}$} \\
\hline First att & $60 \pm 4$ & $40 \pm 3$ & $50 \pm 3$ \\
\hline Second att & $120 \pm 5$ & $60 \pm 3$ & $60 \pm 4$ \\
\hline Third att & $150 \pm 7$ & $65 \pm 5$ & $90 \pm 6$ \\
\hline \multicolumn{4}{|l|}{$\begin{array}{l}\text { Time spent by patients to use the } \\
\text { device (seconds) }\end{array}$} \\
\hline First att & $110 \pm 4$ & $40 \pm 3$ & $40 \pm 3$ \\
\hline Second att & $130 \pm 6$ & $50 \pm 4$ & $50 \pm 5$ \\
\hline Third att & $150 \pm 8$ & $60 \pm 5$ & $60 \pm 4$ \\
\hline \multicolumn{4}{|l|}{ Patients' characteristics } \\
\hline Age $($ mean $\pm S D)$ & $55 \pm 18$ & $54 \pm 18$ & $56 \pm 18$ \\
\hline Sex $(\%$ male $)$ & $47 \%$ & $49 \%$ & $45 \%$ \\
\hline Disease (\% COPD) & $47 \%$ & $48 \%$ & $47 \%$ \\
\hline $\begin{array}{l}\text { Previous experience with inhalation } \\
\text { devices }\end{array}$ & $64 \%$ & $67 \%$ & $63 \%$ \\
\hline $\begin{array}{l}\text { Previous instruction to use of } \\
\text { inhalation devices }\end{array}$ & $61 \%$ & $64 \%$ & $62 \%$ \\
\hline \multicolumn{4}{|l|}{ Patients' perception } \\
\hline $\begin{array}{l}\text { Which device seems easier to use? } \\
\text { (patients' opinion) }\end{array}$ & $2 \%$ & $46 \%$ & $41 \%$ \\
\hline \multicolumn{4}{|l|}{ Critical aspects of usability } \\
\hline $\begin{array}{l}\text { Operational difficulties in use } \\
\text { (patients' claim) }\end{array}$ & $53 \%$ & $38 \%$ & $40 \%$ \\
\hline $\begin{array}{l}\text { Operational difficulties in use } \\
\text { (nurse's assessment) }\end{array}$ & $88 \%$ & $29 \%$ & $17 \%$ \\
\hline $\begin{array}{l}\text { Number of attempts before } \\
\text { achieving the first proper actuation }\end{array}$ & $2.6 \pm 1.1$ & $1.6 \pm 0.8$ & $1.6 \pm 1.0$ \\
\hline Success rate at the first attempt & $18.0 \%$ & $55.7 \%$ & $62.4 \%$ \\
\hline $\begin{array}{l}\text { Number of attempts before } \\
\text { achieving a proper actuation } \\
\text { (after failure of the first attempt) }\end{array}$ & $3.0 \pm 0.8$ & $2.4 \pm 0.6$ & $2.7 \pm 1.0$ \\
\hline $\begin{array}{l}\text { Total time needed for the first } \\
\text { proper actuation** (seconds) }\end{array}$ & $615 \pm 301$ & $150 \pm 95$ & $170 \pm 137$ \\
\hline
\end{tabular}

Notes: Data are presented as mean \pm standard deviation unless indicated. *Number of operations to prepare the inhalation. **Including patient time and the nurse's demonstration time.

Abbreviations: Att, attempt for the proper use of each device; B, Breezhaler; COPD, chronic obstructive pulmonary disease; G, Genuair; R, Respimat; SD, standard deviation. preparation was significantly lower with devices $G$ and $R$, that is, 150 seconds with $\mathrm{G}$ and almost 180 seconds with $\mathrm{R}$, but more than 600 seconds with $\mathrm{B}(P<0.0001)$. All pairwise comparisons are detailed in Table 2.

The cost related to the training actions amounted to $€ 0.51$ per minute of work. Actually, the total training cost per patient (including the nurse's time for demonstration and that for attending the patients' maneuvers) was $€ 1.38 \pm € 1.21$ (interquartile range [IQR]: 0.42-2.44). Device B was found to be the most expensive in terms of cost per patient $(€ 2.35 \pm € 1.26$ [IQR: 1.52-4.04]), which was three to four times higher than that of devices $\mathrm{G}$ and $\mathrm{R}$. Both devices $\mathrm{G}$ and $\mathrm{R}$ induced a cost of $<€ 1$ per patient, with negligible differences between each other (Figure 1).

Devices $\mathrm{G}$ and $\mathrm{R}$ proved quite similar from this point of view: $\mathrm{R}$ was the easiest to use according to the nurse's judgment $(P<0.05)$, while $\mathrm{G}$ needed less attempts before achieving proper actuation in patients who failed in the first attempt $(P<0.05)$. However, the mean total number of attempts was not significantly higher with device $\mathrm{C}$ because it proved to be the easiest device to learn to use, with a success rate of more than $60 \%$ in the first attempt. Also, the total time required for a proper actuation (ie, the time that includes the patients' time for learning and practicing using each device, and the nurse's training time) was very similar with $\mathrm{G}$ and R. Obviously, the cost per patient was also similar; in more than $75 \%$ of patients, the cost was lower than $€ 1$ with both the devices: IQR $0.34-0.84$ for device $\mathrm{G}$ and $0.42-0.93$ for device R.

Asthma and COPD patients showed a very similar trend. Results of subgroup analyses confirmed the presence of only mild differences between asthma and COPD patients in terms of their behavioral attitude to the devices and the corresponding training cost (Table 3, Figure 2). These small differences were considered to be likely due to the characteristics of patients: as expected, asthma patients were significantly younger (44 vs 68 years, $P<0.0001$ ), but originally less trained in the use of inhalation devices $(56 \%$ vs $72 \%, P<0.005)$.

Table 2 Pairwise comparison results

\begin{tabular}{|c|c|c|c|c|c|c|c|c|c|c|}
\hline \multicolumn{3}{|c|}{$\begin{array}{l}\text { Number of attempts } \\
\text { before achieving } \\
\text { correct preparation }\end{array}$} & \multicolumn{3}{|c|}{$\begin{array}{l}\% \text { success at the first } \\
\text { attempt }\end{array}$} & \multicolumn{3}{|c|}{$\begin{array}{l}\text { Number of attempts before } \\
\text { achieving proper actuation } \\
\text { (after failure of } \\
\text { the first attempt) }\end{array}$} & \multicolumn{2}{|c|}{$\begin{array}{l}\text { Total time needed for the } \\
\text { first proper preparation* } \\
\text { (seconds) }\end{array}$} \\
\hline & G & $R$ & & G & $R$ & & G & $\mathrm{R}$ & G & $R$ \\
\hline$B$ & $>$ & $>$ & $B$ & $<$ & $<$ & B & $>$ & $>$ & $>$ & $>$ \\
\hline G & & & G & & & G & & $<$ & & $<$ \\
\hline
\end{tabular}

Notes: Row versus column: " $>$ " means that value measured for the device in the row is greater than the value of the device in the column (vice versa for " $<$ "); white cells represent comparisons that did not reach statistical significance (no differences were detected according to the available data). *Including patient time and nurse demonstration. Red cell: $P<0.000$ I; green cell: $P<0.0$ I; dark green cell: $P<0.05$.

Abbreviations: $B$, Breezhaler; $G$, Genuair; R, Respimat. 
Total nurse cost of device explanation

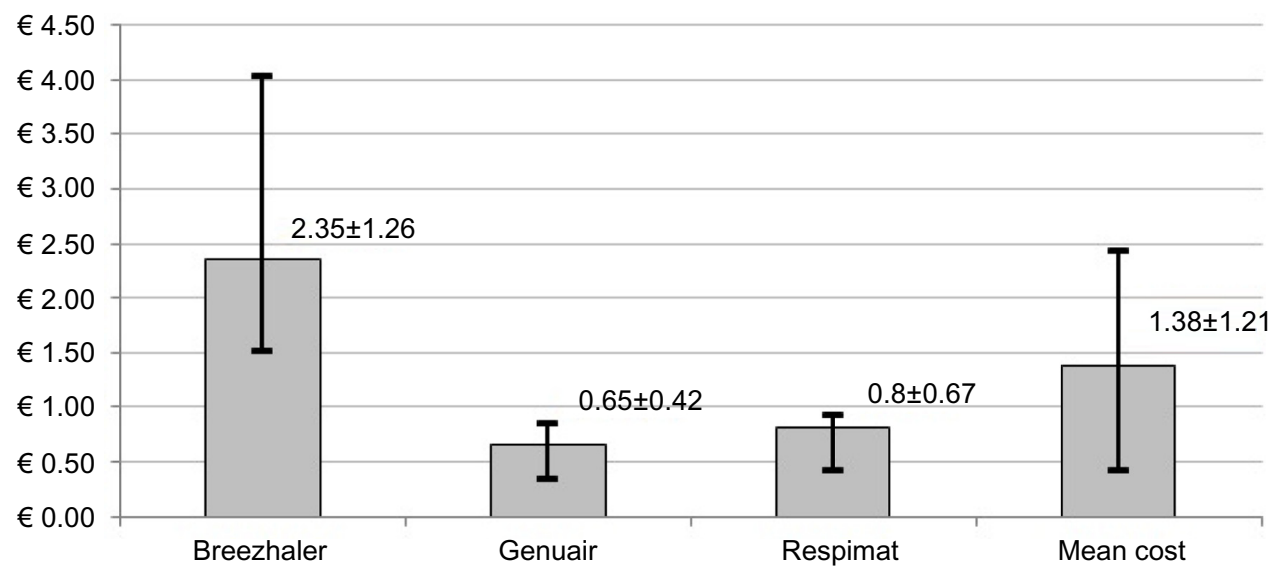

Figure I Cost per patient as the time spent by the nurse in explaining how to use the device to each patient.

Note: Data for each device are expressed as mean \pm standard deviation; for each bar, the line between the notches represents the interquartile range.

\section{Discussion}

Inhalation is the preferred route for delivering respiratory drugs because therapeutic agents reach the lungs directly, and it offers a more rapid onset of action, smaller doses of drugs, and a better efficacy-to-safety ratio., ${ }^{1,12-14}$

Devices for inhalation represent a crucial issue of respiratory treatment (particularly if long-lasting) because per se they are able to affect the therapeutic outcomes substantially and independently of the molecules used. Several factors depending on the devices can, in fact, contribute to the effectiveness of treatment, such as inhalation of a sufficient respirable fraction of drugs, reproducibility of doses, and the understanding and easiness of use, particularly in young people and in elderly. ${ }^{15-20}$

In particular, patient usability and acceptability of inhaled devices are still regarded as two relevant factors because the understanding and reproduction of the sequential maneuvers for their proper actuation can influence the effectiveness of the patient's treatment substantially. ${ }^{2-5,14,16,21-24}$
The presence of critical aspects in handling of the inhalation devices represents a crucial point, particularly in the case of metered-dose inhalers, which can be differently characterized according to their original technological characteristics ${ }^{22,25}$ and the number of actions needed for their actuation. ${ }^{5}$ Data of the present study confirmed that the patterns of usability of devices B, G, and R are heterogeneous, but also showed, for the first time to our knowledge, that these specific features can lead to significant differences in terms of their economic impact.

It is well known that inhalation devices are frequently prescribed by physicians without taking into account 'patients' opinions. Nevertheless, in our study, we decided to investigate the relationship between the patients' perception and the proper and effective use of devices in real life (checked and evaluated independently by a well-trained professional nurse). Patients tested all devices until they used them correctly, that is, until their first successful actuation: once properly actuated for the first time, patients were obviously presumed to be able

Table 3 Data of efficiency for each device in both asthma and COPD subjects

\begin{tabular}{|c|c|c|c|c|c|c|}
\hline & \multicolumn{2}{|l|}{ B } & \multicolumn{2}{|l|}{ G } & \multicolumn{2}{|l|}{$\mathbf{R}$} \\
\hline & Asthma & COPD & Asthma & COPD & Asthma & COPD \\
\hline $\begin{array}{l}\text { Number of attempts before achieving the } \\
\text { first proper actuation }\end{array}$ & $2.4 \pm 1.0$ & $2.8 \pm 1.0$ & I. $.5 \pm 0.8$ & $1.7 \pm 0.8$ & $1.6 \pm 1.1$ & $1.6 \pm 0.9$ \\
\hline Success rate at the first attempt (\%) & 24.0 & 11.4 & 66.9 & 43.4 & 64.2 & 60.3 \\
\hline $\begin{array}{l}\text { Number of attempts before achieving a proper } \\
\text { actuation (after failure of the first attempt) }\end{array}$ & $2.9 \pm 0.8$ & $3.1 \pm 0.8$ & $2.5 \pm 0.8$ & $2.3 \pm 0.5$ & $2.8 \pm 1.1$ & $2.6 \pm 0.9$ \\
\hline $\begin{array}{l}\text { Total time required for the first proper } \\
\text { actuation* (seconds) }\end{array}$ & $562 \pm 298$ & $674 \pm 295$ & $137 \pm 98$ & $164 \pm 89$ & $172 \pm 148$ & $167 \pm 124$ \\
\hline
\end{tabular}

Notes: Data are presented as mean \pm standard deviation unless indicated. *Including patient time and nurse demonstration. Abbreviations: B, Breezhaler; COPD, chronic obstructive pulmonary disease; G, Genuair; R, Respimat. 


\section{Total nurse cost of device explanation (subgroup results) $\square$ Asthma}

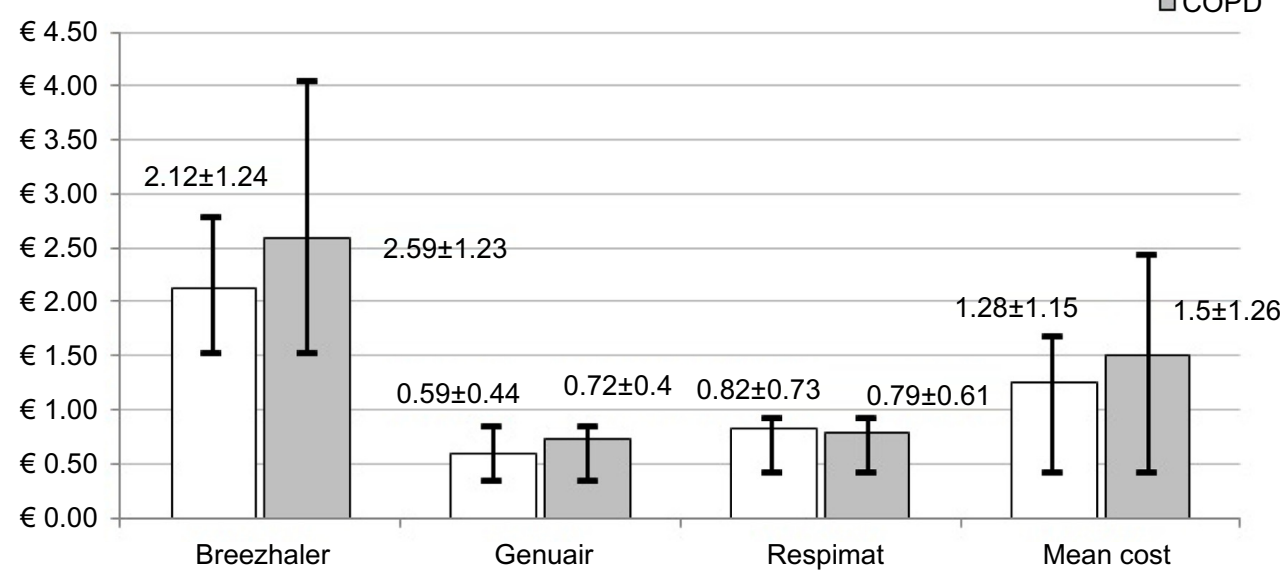

Figure 2 Cost per patient as the time spent by the nurse in explaining how to use the device in asthma and COPD patients. Note: Data for each device are expressed as mean \pm standard deviation; for each bar, the line between the notches represents the interquartile range. Abbreviation: COPD, chronic obstructive pulmonary disease.

to retain and further reproduce the correct procedure when needed. In other words, their first correct actuation was the proof of their acquired skill in the device's usability. Finally, patients did not have to choose the device, but only had to indicate which device seemed easier to use according to the procedure experienced by them for actuation.

From the point of view of usability, device B proved to be the most critical and difficult to use in real life, either when compared to the analyzed DPI (device G) or to the SMI device (device R). In particular, $<3 \%$ of patients chose device B as the easiest to use and more than $50 \%$ of patients met with some relevant difficulties in practicing use of this device, and these data confirm the results of a previous study. ${ }^{26} \mathrm{As}$ a consequence, the corresponding economic impact was the highest. In other words, when compared to that of the other two devices, the nurse's training time required for ensuring a proper inhalation via device $\mathrm{B}$ corresponded to a mean cost increment of $€ 1.5-€ 2.0$ per patient.

The relevance of the time spent to allow the first proper actuation of each device is crucial in our opinion, because it does not reflect the patient's perception concerning the difficulties possibly encountered in usability of each device, but measures objectively the true difficulties faced by a patient in using each device in real life by means of a simple and quantitative measurement (in seconds). This quantity of time inevitably corresponds to an economic impact, either in terms of nurses' work time or lower therapeutic outcomes due to ineffective therapeutic inhalations of respiratory drugs. This particular aspect was never taken into account, to our knowledge, when considering the pharmacoeconomics of respiratory treatments. In general, attention had been almost uniquely focused on calculation of major components of asthma and COPD cost of illness such as; hospital admissions, medical visits, drugs consumption as direct costs, and work and school days off, and lost opportunities as indirect costs. Nevertheless, the impact of specific training aimed to ensure proper usability of devices is not negligible in economic terms as it approximately corresponds to the annual salary of two professional nurses. The calculation of this particular component of costs might then contribute to define a more precise pattern of convenience for each device.

Usually, the major criteria for prescribing one inhalation device are mainly related to its "apparent easiness of use" (based on patients' perceptions), without any controlled testing of the true capability of the patients in reproducing the procedures required for the proper actuation with that device. When prescription is based on the evidence of specific training, some firm beliefs can change dramatically, and the original "apparent easiness of use" may objectively switch to "difficult to use" in handling the same device, as was shown in the present study when devices $B, G$, and R were compared.

\section{Conclusion}

Substantial differences exist in patients' acceptability and handling of the three inhalation devices. In order to provide a complete picture of each device's performance, the training time spent for achieving the first proper inhalation should be regarded as a reliable measure for characterizing each device 
in terms of usability, which is then added to the usual indices for judgment.

Correspondingly, the choice of one device might also be supported objectively by the cost of the specific training for that device. Actually, this variable would contribute to further characterize the performance of each device in economic terms. The domains for the convenience of choice would then be substantially extended in favor of the payer's point of view also.

Device $\mathrm{R}$ as an SMI and device $\mathrm{G}$ as an metered-dose inhaler proved to be the most convenient in economic terms also.

\section{Disclosure}

The authors report no conflicts of interest in this work.

\section{References}

1. Cross S. Asthma inhalation delivery systems: the patient's viewpoint. J Aersol Med. 2001;14 (Suppl 1):S3-S7.

2. Virchow JC, Crompton GK, Dal Negro RW, et al. Importance of inhaler devices in the management of airway diseases. Respir Med. 2008;102:10-19.

3. Lenney J, Innes JA, Crompton GK. Inappropriate inhaler use: assessment of use and patient preference of seven inhalation devices EDICI. Respir Med. 2000;94(5):496-500.

4. Self TH, Arnold LB, Csosnowski LM, Swanson JM, Swanson H. Inadequate skill of health care professionals in using asthma inhalation devices. J Asthma. 2007;44:593-598.

5. Dal Negro RW, Povero M. Acceptability and preference of three inhalation devices assessed by the Handling Questionnaire in asthma and COPD patients. Multidiscip Respir Med. 2016;11:5.

6. Dal Negro RW, Guerriero M. Cultural and linguistic testing of the Handling Questionnaire: a specific instrument for assessing the patient's acceptability of dry powder inhalers. Monaldi Arch Chest Dis. 2008;69(4):170-177.

7. Perpina Tordera M, Viejo JL, Sanchos J, et al. Assessment of patient satisfaction and preferences with inhalers in asthma with the FSI-10 Questionnaire. Arch Broncopneumol. 2008;44:346-352.

8. Hanada S, Wada S, Ohno T, Sawaguchi H, Muraki M, Tohda Y. Questionnaire on switching from the Tiotropium Handihaler to the Respimat inhaler in patients with chronic obstructive pulmonary disease: changes in handling and preferences immediately and several years after the switch. Int J Obstruct Pulmon Dis. 2015;10:69-77.
9. Favalli EG, Marchesoni A, Colombo GL, Sinigaglia L. Pattern of use, economic burden and vial optimization of infliximab for rheumatoid arthritis in Italy. Clin Exp Rheumatol. 2008;26:45-51.

10. Harmonised Indices of Consumer Prices (HICPs), European Commission EuroStat; 2014. Available from: http://ec.europa.eu/eurostat/tgm/table. do $?$ tab $=$ table $\&$ init $=1 \&$ language $=$ en $\&$ pcode $=$ tec $00027 \&$ plugin $=1$. Accessed December, 2015.

11. R Core Team R: A language and environment for statistical computing $R$ Foundation for Statistical Computing, Vienna, Austria; 2013. Available from: http://www.r-projectorg/. Accessed December, 2015.

12. Magnussen H. Novolizer: how does it fit into inhalation therapy? Curr Med Res Opin. 2005;21 (Suppl 4):S39-S46.

13. Barnes PJ. Introduction: how can we improve asthma management? Curr Med Res Opin. 2005;21 (Suppl 4):1-3.

14. Melani AS. Inhalatory therapy training: a priority challenge for the physician. Acta Biomed. 2007;78:233-245.

15. Newman SP, Busse WW. Evolution of dry powder inhaler design, formulation, and performance. Respir Med. 2002;96:293-304.

16. Wieshammer S, Dreyhaupt J. Dry powder inhalers: which factors determine the frequency of handling errors? Respiration. 2008;75: $18-25$.

17. Chapman KR, Fogarty CM, Peckitt C, et al. Delivery characteristics and patients' handling of two single-dose dry powder inhalers used in COPD. Int J Chron Obstruct Pulmon Dis. 2011;6:353-356.

18. Barrons R, Pegram A, Borrens A. Inhaler device selection: special considerations in elderly patients with chronic obstructive pulmonary disease. Am J Health Syst Pharm. 2011;68:1221-1232.

19. Anderson P. Use of Respimat soft mist inhaler in COPD patients. Int $J$ Chron Obstruct Pulmon Dis. 2006;1:251-259.

20. Henriet AC, Marchand-Adam S, Mankikian J, Diot P. Respimat ${ }^{\mathbb{}}$, first soft mist ${ }^{\mathrm{TM}}$ inhaler: new perspectives in the management of COPD. Rev Mal Respir. 2010;27:1141-1149.

21. Anderson P. Patient preference for and satisfaction with inhaler deviced. Eur Respir Rev. 2005;96:109-116.

22. Chrystin H. Do patients show the same level of adherence with all dry powder inhalers? Int J Clin Pract Suppl. 2005;149:19-25.

23. Lavorini F, Fontana GA. Inhaler technique and patient's preference for dry powder inhaler devices. Expert Opin Drug Deliv. 2014;11:1-3.

24. Dal Negro RW, Bonadiman L, Tognella S, Bricolo FP, Turco P. Extent and prevalence of cognitive dysfunction in chronic obstructive pulmonary disease, chronic non-obstructive bronchitis, and in asymptomatic smokers, compared to normal reference values. Int J Chron Obstruct Pulmon Dis. 2014;9:675-683.

25. Dal Negro RW. Dry powder inhalers and the right things to remember: a concept review. Multidiscip Respir Med. 2015;10(1):13.

26. Pascual S, Feimer J, De Soyza A, et al. Preference, satisfaction and critical errors with Genuair and Breezhaler inhalers in patients with COPD: a randomized, cross-over, multicenter study. NPJ Prim Care Respir Med. 2015:25:15018.
ClinicoEconomics and Outcomes Research

\section{Publish your work in this journal}

ClinicoEconomics \& Outcomes Research is an international, peerreviewed open-access journal focusing on Health Technology Assessment, Pharmacoeconomics and Outcomes Research in the areas of diagnosis, medical devices, and clinical, surgical and pharmacological intervention. The economic impact of health policy and health systems

\section{Dovepress}

organization also constitute important areas of coverage. The manuscript management system is completely online and includes a very quick and fair peer-review system, which is all easy to use. Visit $\mathrm{http}: / /$ www.dovepress.com/testimonials.php to read real quotes from published authors. 